\title{
An Analysis of the Ways to Transform Scientific Research Achievements into Teaching Resources in Vocational Education Institutions
}

\author{
Dalong $\mathrm{Li}^{\mathrm{a}}{ }^{\text {, }}$, Weiliang Gaob and Xia Dong ${ }^{\mathrm{c}}$ \\ Navy Aviation Engineering Academy Qingdao Branch, Qingdao 266041, China \\ àhkldldl@163.com, b gaoweiliang_2000@163.com, cxxdo@163.com \\ *corresponding author
}

Keywords: transformation of scientific research results, teaching resources, vocational education.

\begin{abstract}
The transformation of scientific research achievements into teaching resources is a complex task. This article first analyses the importance and feasibility of this transformation. It then suggests some effective directions and strategies for transforming scientific research achievements into teaching resources in vocational education institutions, according to the status and problems.
\end{abstract}

\section{Introduction}

In the vocational education transformation, especially in the modern era of rapid development of science and technology, with many new knowledge, new technologies and new equipment as the representative of the educational institutions continue to emerge at the same time, With the deepening of the teaching reform of vocational education institutions, the requirements for teaching resources close to the practical application background are also getting higher and higher. However, the results of scientific research are generally low conversion rate, lack of service teaching ability, but also to a certain extent, caused a waste of scientific research funding. Therefore, how to take effective measures to convert scientific research into teaching resources in time is the urgent task facing the teaching and research management departments of educational colleges and universities, and it is also an important measure to deepen the teaching reform.

\section{The Significance and Feasibility of Transforming Scientific Research into Teaching Resources}

\subsection{Significance}

(1) Promote the transformation of scientific research

At present, the educational institutions of academic institutions into the teaching resources of the situation is not optimistic, scientific research results conversion efficiency is not high. And scientific research results are also a single form of transformation, mainly papers, experimental reports, monographs and other common forms. Scientific research into teaching resources will expand the channels of scientific research transformation, enrich the form of scientific research into the transformation.

(2) Rich teaching resources

The teaching resources of this article mainly refers to the basic teaching resources such as curriculum resources, library materials and laboratory (equipment). Teaching and research department through the transformation of scientific research for the teaching sector to increase teaching resources, update the teacher's teaching philosophy and teaching content, direct support for school teaching; teachers through scientific research to improve their professional knowledge and teaching level, and ultimately establish scientific research results of practical teaching of advanced concepts. 
(3) Enhance teachers' scientific research and teaching ability

The two main functions of the institutions are teaching and research, college teachers not only to engage in teaching work, but also to do scientific research work. Only non-teaching teachers seem to stand in front of the academic, in fact, out of the students, lost the basis of research, research results value and usefulness is not high. Those who study how to turn scientific research into teaching materials can improve their research and teaching skills.

(4) Stimulate students' enthusiasm for learning

From the scientific research results of teaching resources to attract the attention of students, their desire for frontier knowledge is the embodiment of their enthusiasm for learning. The provision of such teaching resources for students is conducive to students more clearly understand their future job needs, is conducive to students more intuitive grasp of the knowledge in the practical application of the method, and also is conducive to students to actively develop innovative consciousness.

\subsection{Feasibility Analysis}

Some of the scientific research produced by the institute comes from teaching, it can directly act on teaching, such as rich curriculum resources, improve teaching methods, improve teaching facilities and so on. Teaching resources, in turn, provide inspiration for research. The two are interacting and interacting with each other. Some of the scientific research produced by the university comes from teaching, it can directly act on teaching, such as rich curriculum resources, improve teaching methods, improve teaching facilities and so on. Teaching resources, in turn, provide inspiration for research. The two are interacting and interacting with each other.

Institute of scientific research results in a broad sense, can be used to serve the teaching resources are teaching. Therefore, the university's scientific research itself is a teaching resource.

From the micro level, teachers' research results and teaching resources are both linked and different. The relationship between the two is mainly reflected in the scientific research results can be transformed into students to learn the curriculum resources, while teaching resources can also provide inspiration for scientific research work, the two complement each other to jointly promote the development of colleges and universities.

\section{The Status and Problems of the Transformation of Scientific Research Achievements into Teaching Resources}

Through the simple interview of the scientific research management department, the educational affairs department and the related teachers, it is found that the process of scientific research transformation to the teaching resources will be influenced by many factors, which is not conducive to the transformation of scientific research results, resulting in lower conversion rate, summed up mainly in the following areas.

\subsection{Scientific Research Results of the Lack of Their Own Applicability}

At present, many college teachers in the choice of research topics usually pursue the perspective of the novelty of research and research areas of uniqueness, to achieve theoretical breakthroughs and innovation, the pursuit of value orientation is the academic and advanced scientific research results. As for the results of scientific research can be transformed into teaching resources and how to convert into teaching resources to consider the issue of little, thus increasing the scientific research results to the teaching of the difficulty of transformation, reducing the conversion rate of scientific research.

\subsection{Scientific Research Results Transformation Consciousness}

Many teachers of scientific research concept is not correct, that the results of scientific research as long as the problem will be everything goes on, only focus on the number of scientific research results, ignoring the scientific research results can be transformed into teaching resources and the consciousness of how to transform the problem is weak. 


\subsection{Scientific Research Transformation Mechanism is not Perfect}

At present, many colleges and universities have established a relatively sound scientific research results into productive forces mechanism, scientific research results to the transformation of productivity is flourishing development. However, the results of scientific research into internal teaching resources is not optimistic, many colleges and universities did not establish a set of practical transformation mechanism, not the scientific research results to the transformation of teaching resources to the university's construction schedule up, some only individual Teachers will be their own scientific research results simply introduced to the students, scientific research to the teaching resources of the environment has not yet established.

\section{The Way to Transform Scientific Research into Teaching Resources}

\subsection{To Carry Out the Top Design, Establish Scientific Research Services to Combat the Advanced Concept of Teaching}

In the early selection of scientific research projects and projects, teachers can not only consider the subject of funding and other aspects, to focus on scientific research and their own professional and the degree of relevance and the feasibility of the transformation and the possibility of the problem, only from this perspective Select the research topics, teachers in the research process is more likely to produce results, but also can produce the scientific research results in an appropriate way to teach students, not only to enhance their own research and teaching ability, and students can get a steady stream of New knowledge, is conducive to the cultivation of innovative talents.

The teaching and research department through the transformation of scientific research for the teaching sector to increase teaching resources, update the teacher's teaching philosophy and teaching content, direct support for school teaching work; teachers through scientific research to improve their professional knowledge and teaching level, and ultimately establish scientific research services to combat the advanced concept of teaching.

\subsection{The Scientific Research gets into the Classroom, Improve the Practical Effect of Practical Teaching}

As the expression of scientific research and the characteristics of the structure and teaching content is different, which led to scientific research cannot be directly as a teaching resource, need to be a certain change, mainly in accordance with the appropriate expansion of scientific research results around the principles of teaching for the rich scientific research The principle of form of expression; according to the student knowledge and scientific research results at the maturity level of appropriate control of teaching content of the depth and breadth of the principle of transformation.

Will be the specific equipment teaching and practical work closely with the collection of scientific research products and services to customers of the typical teaching case; scientific research into the professional teaching materials, and fully reflect the rational integration of teaching materials features; professional teachers into the first scientific research Line, to understand the production of scientific research products production process, grasp the technical aspects of feedback to the teaching design to go.

\subsection{Establish a Scientific Research Sharing Platform, Broaden the Actual Teaching Resources}

Establishing the Inter - school Sharing Platform of Scientific Research Achievements in Educational Institutions. A single professor or research group of scientific research is limited, for the transformation of teaching resources for the results are not rich enough. Therefore, the school to play the overall advantages of scientific research, the establishment of relevant disciplines or professional research results of the teaching resource library, through the network to provide a variety of information to achieve scientific research achievements in the exchange of resources to exchange resources sharing, sharing and sharing. 
Publish the publication. Through the school teaching management department of the magazine, so that teachers understand the transformation of scientific research on the latest information, as well as the relevant policy issues, published by academics to write the technical transfer of professional articles.

\subsection{Constructing the Evaluation System of Scientific Research Achievements to Teaching Resources}

Scientific research management departments and teaching management departments to strengthen their own scientific research results to the transformation of teaching resources awareness, scientific research management departments need to transform scientific research into teaching resources into the scientific research results evaluation system, the scientific research results to the teaching of the transformation of the whole situation management and supervision, and effectively play the role of the department in the transformation of scientific research to teaching resources. In the teaching of teachers and the teaching of the assessment and evaluation of the situation, the teaching management department should focus on teachers to consider the new knowledge into the teaching content of the situation and through the teaching of new students to improve the performance and enhance the situation. Scientific research management departments and teaching management departments should be independent of each other, their responsibilities, while scientific research to the teaching resources in the process of transformation and mutual cooperation, and jointly promote the successful transformation of scientific research into teaching resources. First of all, the establishment of scientific research to the actual transformation of teaching resources to stimulate the transformation. Second, the development of scientific research into the evaluation criteria. Third, through the teacher survey and the way to visit, the evaluation team to test the scientific research results in the shared platform in the radiation effect. If the teachers share their own scientific research, and promote the teaching of other teachers and the ability to enhance the ability to determine the results of the teaching transformation effect.

\section{Summary}

The transformation of scientific research achievements into teaching resources is not only related to the results of individuals, but also the need for scientific research management and teaching management departments to work together to complete, is a complex task. It is helpful to improve the quality of teaching and the quality of personnel training by overcoming the obstacles in the process of transforming the results into teaching resources and strengthening the research on the transformation of the results into teaching resources.

\section{References}

[1]. Binbin Lin, Chuangang Zhang. Jun Wang, Song Gao, An Analysis of the Related Problems in the Course of the Integration of Military Teachers [J]. Science and Technology Economic, 2016 (2);

[2]. Dan Li, A Study on the Incentive Mechanism of Scientific Research Achievement Transformation in Provincial Universities of Jilin Province [J]. Journal of Changchun Normal University, 2013 (11):107-108;

[3]. Hanling Yu, Research on the Management Mode of Longitudinal Scientific Research Projects in Colleges and Universities [D]. Master Degree Thesis, Beijing Jiaotong University, (2015);

[4]. Jia Huang, Mechanism Research on Transforming Scientific Research Results at Colleges into Teaching Resources [D]. Master Degree Thesis, Wuhan University of Technology, (2014);

[5]. Jie Xu etc, A Study on the Strategies of Transforming Scientific Research Achievements into Teaching Resources [J]. Heilongjiang Education (Higher Education Research \& Appraisal), 2016(01):6-7;

[6]. Xiaofeng Zhu, Research on the Teaching Transformation Mechanism of Scientific Research 
Achievements in Higher Vocational Colleges - Taking Hangzhou Higher Vocational Colleges as an Example [J]. China Business \& Trade ,2013 (30):187-188;

[7]. Xiaohua Cao etc, Scientific research into a comprehensive, design experiment teaching exploration and practice[J]. Chinese Journal of Chemical Education, 2009, 30 (11);

[8]. Xiaoyan Jing, The Role of Scientific Research in Improving the Teaching Level of Basic Courses[J]. University Education ,2013 (20):77-78. 